Pak. J. Anal. Environ. Chem. Vol. 21, No. 1 (2020) 102 - 106

\title{
Assessment of the Effect of Glycine, Oxalic Acid and Nitrogen-Phosphorus-Potassium (NPK) Fertilizer as Nutrient Supplement Using Phosphate and Oxalic Acid as Indices
}

\author{
Temitope Olabisi Abodunrin* and Yemisi T. Afolabi \\ Department of Physical Science College of Pure Applied Sciences, Landmark University \\ P.M.B. 1001 Omu-Aran Kwara State, Nigeria. \\ *Corresponding Author Email: abodunrim.temitope@lmu.edu.ng \\ Received 14 March 2019, Revised 30 December 2019, Accepted 21 May 2020
}

\begin{abstract}
This study evaluated the release profiles of phosphate and oxalic acid in soils treated with oxalic acid a low molecular weight organic acid and glycine an amino acid compared with NPK fertilizer monitored over a period of 21 days. The soil treated with oxalic acid and glycine released higher phosphate and oxalic acid than that treated with NPK fertilizer. The soil treated with oxalic acid released higher phosphate than that which was treated with glycine while higher oxalic acid was observed in the soil treated with glycine rather than for that treated with oxalic acid. Significant effects were observed between the treatment and the length of time for phosphate release $(\mathrm{P}<0.05)$ while for the release of oxalic acid, there was no significant effect between the treatment $(\mathrm{P}>0.05)$ but with increase in length of time $(\mathrm{P}<0.05)$. This demonstrates the efficient ability of oxalic acid and glycine as substitutes for phosphate fertilizers.
\end{abstract}

Keywords: Glycine, Oxalic acid, Phosphate, NPK, Release profile.

\section{Introduction}

Organic and amino acids are an important class of organic compounds common in soil rhizosphere which are exuded by plants as an adaptive response to counter nutrient deficiencies [1,2]. Organic acids have been known to alleviate and improve nutrient tolerance deficiencies, mobilize and transport nutrients, regulate physiological process such as decrease in lipid peroxidation, improve antioxidant enzyme activity and increase contents for osmotic regulation [3,4]. The transformation of phosphorus are promoted by low molecular weight organic acids [5].

Oxalic acid is important in soil interaction because of their involvement in nutrient acquisition and reduction of stress strategies in plants, mobilization of poorly soluble nutrients, improvement of bioavailability, detoxification of soils through metal chelation support, vegetative improvement and restoration, alleochemical interactions, aluminium and pollutant detoxification, control of the activities of enzymes and food-web interactions $[2,6,7]$.

Phosphorus recognized as a key nutrient in plant nutrition and important for the growth and development of crops. It exudes organic acids as a means of adaptability of phosphorus deficiencies [8]. The presence of phosphorus in plant nutrition may stimulate ecological processes, plant growth, nutrient mineralization which leads to improvement in the soil nutrient status and good yields $[9,10]$. 
Best management practices for food and the environment requires the use of organic production and or reduced application of fertilizers and pesticides [11]. In view of this, the study was carried out to check the release profiles of oxalic acid and glycine compared with NPK fertilizer added as nutrient supplement using phosphate and oxalic acid as indices.

\section{Materials and Methods}

The reagents used were obtained from Landmark University's Chemistry Laboratory. Glycine (Loba Chemie, India), Oxalic Acid (Sigma GmbH), Hydrazine Sulphate (SCP, UK), Sodium hydroxide (Carlo Erba Reagents France), Sodium hydrogen carbonate (Breckland, UK), Bromophenol blue (Kemlight, India), Potassium heptaoxodichromate (Breckland, UK) and Ammonium molybdate (Fisher Scientific, UK). The nitrogen phosphorus potassium (NPK) with ratio 15-15-15 was collected from Landmark University Teaching and Research Farm.

The release studies was carried out under laboratory conditions using loamy soils collected from Landmark University Teaching and Research farm at depth of $25 \mathrm{~m}$. The soil samples were airdried and sieved with $20 \mu \mathrm{m}$ sieve before use. The organic and amino acids selected for the study were glycine and oxalic acid while the fertilizer used was NPK. Each of the treatment was applied to the soil using a ratio of $1 \mathrm{~g}$ nutrient to $200 \mathrm{~g}$ of soil maintained at room temperature, soil $\mathrm{pH}, 30 \%$ water holding capacity and 21 days incubation. The absorbance was recorded on a JENWAY 6510 Spectrophotometer.

\section{Extraction and determination of phosphate}

A single step extraction was carried out using the report by Turner et.al. (2005) and Mussa et. al. (2009) with slight modification. $30 \mathrm{~mL}$ of extractant solution containing $42 \mathrm{~g}$ of sodium hydrogen carbonate dissolved in $50 \%$ sodium hydroxide at $\mathrm{pH} 8.5$ was added to $5 \mathrm{~g}$ of soil samples. The mixture was allowed to soak for an hour and then placed in a centrifuge for $5 \mathrm{~min}$ at $3,000 \mathrm{rpm}[12]$. An aliquot of the extracted sample was treated with $1 \mathrm{~mL}$ of ammonium molybdate and $0.4 \mathrm{~mL}$ of hydrazine sulphate and the solution made up to $10 \mathrm{~mL}$ with deionized water. The mixture was placed in a hot water bath for $15 \mathrm{~min}$ until the development of a blue colour. After which the solutions were allowed to cool and their absorbance was recorded at a wavelength of 830 nm [13].

\section{Extraction and determination of oxalic acid}

The oxalic acid present in the soil samples were extracted by the addition of $30 \mathrm{~mL}$ deionised water to $5 \mathrm{~g}$ soil samples [12]. The mixture was left for an hour to soak after which it was subjected to centrifugation for $5 \mathrm{~min}$ at a speed of $3,000 \mathrm{rpm}$ [14]. Aliquots of the extracts were treated with $0.1 \mathrm{~mL}$ bromophenol blue and $0.2 \mathrm{~mL}$ $\mathrm{K}_{2} \mathrm{Cr}_{2} \mathrm{O}_{7}$ and the solution was made up to $10 \mathrm{~mL}$. The resulting solution was placed in a $60^{\circ} \mathrm{C}$ water bath and quenched with $0.5 \mathrm{~mL}$ of $\mathrm{NaOH}$ for 10 min. The absorbance of the final solutions was recorded at $600 \mathrm{~nm}$ [15].

\section{Statistical analyses}

The data and calculations obtained from the spectrophotometric studies on oxalic acid and phosphate release in soils treated with NPK, glycine and oxalic acid were performed using SPSS 20 programme. The data was analysed using mean and analysis of variance while the regression equations were fitted to the data to obtain the oxalic acid content and phosphate content. The level of significance was measured at $95 \%$.

\section{Results and Discussion}

The availability of nutrient is totally dependent on the amount of nutrient released into the soil. This study evaluated the nutrient availability in soils treated with low molecular weight organic acid and amino acid - glycine and oxalic in comparison with standard fertilizer NPK using oxalic acid and phosphate as indices. Several studies have established that plants excrete organic acids as adaptive response in nutrient deficient environment [1-3,5,7,16,17]. 
Effect of nutrient application on phosphate release

The graphical illustration in Fig. 1 showed that the highest phosphate was released by the treatments in the order: oxalic acid > glycine > NPK which corresponds to $40 \%, 38 \%$ and $24 \%$, respectively. The NPK, oxalic acid and glycine treatment released treatment in the range $0-1400$ $\mu \mathrm{g}, 100-2600 \mu \mathrm{g}$ and $0-2500 \mu \mathrm{g}$ respectively. As depicted in Fig. 2, the maximum phosphate release occurred for all the treatments on day 5 . Increase in cumulative phosphate was observed as the days went by. The data analysis as illustrated in Table 1 which involved the use of two-way anova showed type of treatment applied and the length of time of release affected the phosphate release significantly. Table 1 showed the treatments significantly affected the concentration of phosphate released $(\mathrm{P}<0.05)$. The length of time also showed significant effect on the release of phosphate $(\mathrm{P}<0.05)$ into the soil as shown in Fig. 1. The significant correlation which was observed with the treatment of soils with oxalic acid and glycine for release of phosphorus is in consonance with studies on plant tolerance and secretion of organic acid under nutrient deficiency. The increase in phosphate release by glycine and oxalic acid may also be due to the dissolution and desorption powers of low molecular weight organic acids [12]. The higher release of phosphate in oxalic acid can be attributed to its lower $\mathrm{pH}$ in solutions due to the presence of two carboxylic groups and its potential to enhance phosphorus availability in ecosystems while the lesser release of phosphate in glycine may be due to the fact that it is neutral in solutions $[2,17,18]$. NPK which released the least amount of phosphate can be attributed to the alkalinity of the soil which have must caused the conversion of phosphate in the fertilizer to tricalcium phosphate a form which is unavailable to the soil [19]. This study showed that more phosphate was released as the nutrients stayed longer in the soil. Increased phosphate presence essentially reduces soil $\mathrm{pH}$, enhances nutrient uptake, increases chlorophyll content and rate of photosynthesis [19]. Higher phosphate implies low mobility and greater saturation that offers greater chemical solubilisation stability. This confirms literature reports that the addition of low molecular weight organic acids immobilize phosphate and make them available for plant uptake. It is also worthy of note that the use of organic acids can replace phosphorus containing fertilizers which would address the problem of phosphate leaching and ensure the safety of the environment $[9,19]$.
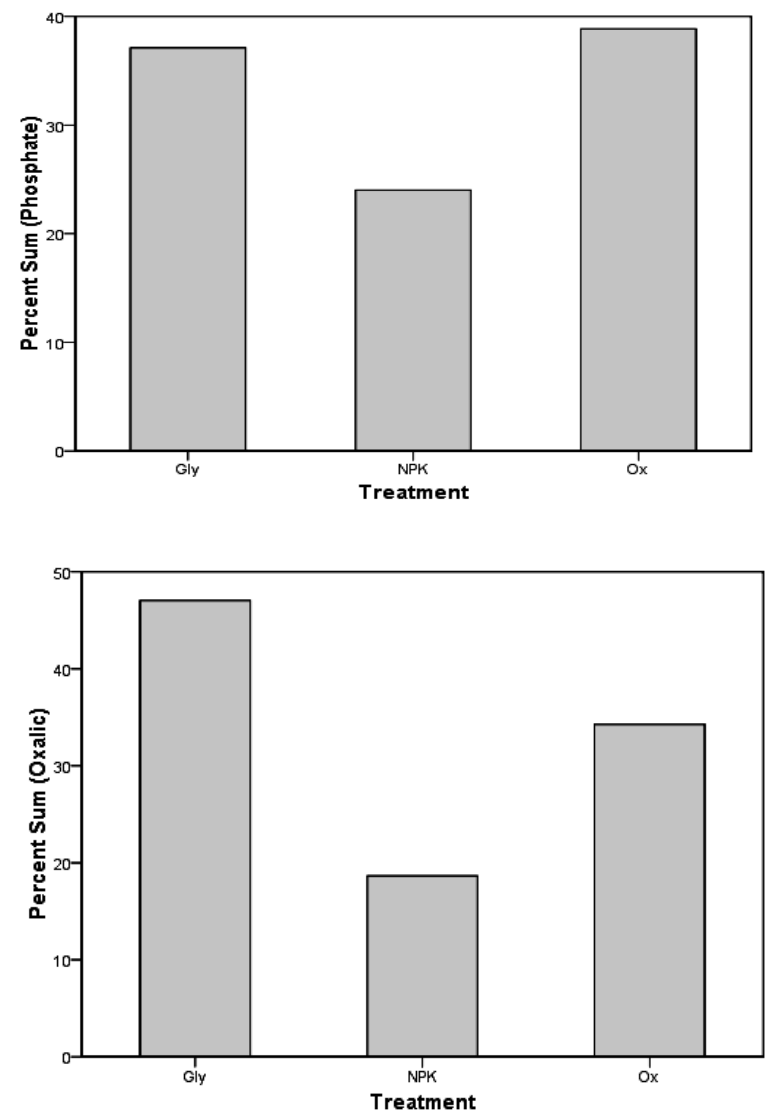

Figure 1. Total phosphate and oxalic acid released

Table 1. Statistical analysis of tests of between-subjects effects for phosphate release.

\begin{tabular}{lccccc}
\hline Source & $\begin{array}{c}\text { Type III } \\
\text { Sum of } \\
\text { Squares }\end{array}$ & df & $\begin{array}{c}\text { Mean } \\
\text { Square }\end{array}$ & F & Sig. \\
\hline $\begin{array}{l}\text { Corrected } \\
\text { Model }\end{array}$ & $.001^{\mathrm{a}}$ & 7 & .000 & 12.119 & .000 \\
Intercept & .003 & 1 & .003 & 262.730 & .000 \\
Treatment & .000 & 2 & $\begin{array}{c}5.756 \mathrm{E}- \\
005\end{array}$ & 5.190 & .028 \\
Days & .001 & 5 & .000 & 14.891 & .000 \\
Error & .000 & 10 & $\begin{array}{c}1.109 \mathrm{E}- \\
005\end{array}$ & & \\
Total & .004 & 18 & & & \\
Corrected & .001 & 17 & & \\
Total & & & & \\
\hline a. R Squared $=.895$ (Adjusted R Squared $=.821)$ & & \\
&
\end{tabular}




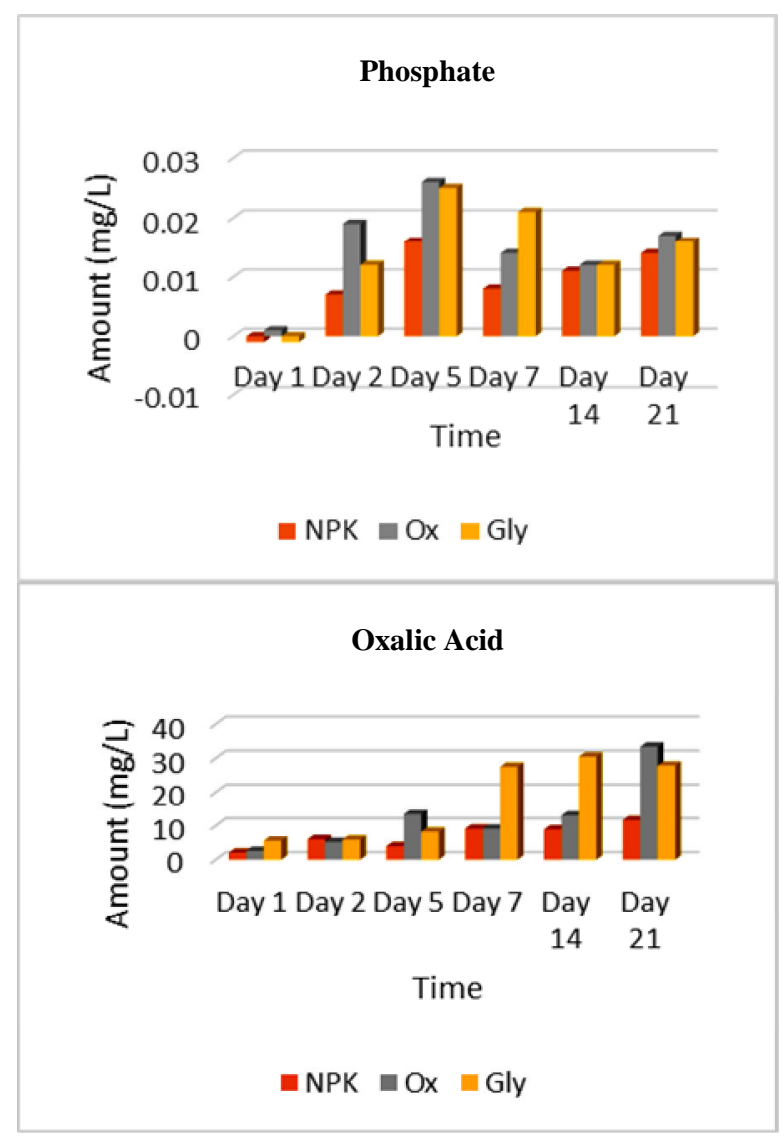

Figure 2. Phosphate and oxalic acid release from NPK, Ox and gly

\section{Effect of nutrient application on oxalic acid release}

The percentage of the treatment released during the period of study were: NPK $19 \%$, oxalic acid $34 \%$ and glycine $46 \%$ reflects an increase in the order of glycine $>$ oxalic $>$ NPK. The range of mean values of oxalic acid present were: 3.3 to $21.72 \mathrm{mg} / \mathrm{L}, 2.63$ to $33.45 \mathrm{mg} / \mathrm{L}$ and 5.63 to 30.52 $\mathrm{mg} / \mathrm{L}$ for treatment with NPK, oxalic acid and glycine. The range of mean values of oxalic acid present for treatment with NPK, oxalic acid and glycine as reported in the study was higher than $1250 \mathrm{nmol} / \mathrm{g}$ predicted for the production of oxalic in soils without any treatment reported in literature $[2,6]$. A steady increase in oxalic acid concentration was observed on all days for glycine and oxalic acid treatment as shown in Fig. 2. Table 2 depicts the two-way anova which showed the significance of the type of treatment applied and the effect of time of release on oxalic acid release. According to Table 2, the treatment showed no significant effect on the amount of oxalic acid $(\mathrm{P}>0.05)$ released with the treatments applied while the amount of oxalic acid released was significantly affected by time $(\mathrm{P}<0.05)$. This depicts that the treatments does not have significant effect while the length of time affected the release of oxalic acid. The higher release of oxalic acid by glycine than oxalic acid may be attributed to the short life of oxalic acid in the environment and the strong ability of oxalic acid to chelate with metal ions present and serve as reducing agent in the soil $[2,18]$.

Table 2. Statistical analysis of tests of between-subjects effects for oxalic acid release.

\begin{tabular}{lccccc}
\hline *Source & $\begin{array}{c}\text { Type III } \\
\text { Sum of } \\
\text { Squares }\end{array}$ & df & $\begin{array}{c}\text { Mean } \\
\text { Square }\end{array}$ & F & Sig. \\
\hline $\begin{array}{l}\text { Corrected } \\
\text { Model }\end{array}$ & $1287.654^{\mathrm{a}}$ & 7 & 183.951 & 4.040 & .023 \\
Intercept & 2804.755 & 1 & 2804.755 & 61.607 & .000 \\
Treatment & 340.554 & 2 & 170.277 & 3.740 & .061 \\
Days & 947.100 & 5 & 189.420 & 4.161 & .026 \\
Error & 455.267 & 10 & 45.527 & & \\
Total & 4547.676 & 18 & & & \\
Corrected & 1742.921 & 17 & & & \\
Total & & & & & \\
\hline
\end{tabular}

a. $\mathrm{R}$ Squared $=.739$ (Adjusted $\mathrm{R}$ Squared $=.556)$

\section{Conclusion}

Oxalic acid and glycine which released higher amounts of phosphate in the study may be due to their ability to lower the $\mathrm{pH}$ which increase solubilisation, displacement and liberation of insoluble phosphate, increase saturation of adsorption sites and decrease binding energy that offer greater stability $[9,19,20]$. The addition of glycine and oxalic acid will be more effective for the treatment of phosphorus deficiencies in soils, useful for application in plants which requires higher phosphorus content for survival, beneficial support for improvement and restoration of vegetation. The increased the presence of phosphate and oxalic acid in the study reflects the ability of glycine and oxalic acid to improve available soil nutrients, soil properties and achieve better productivity than NPK. Based on the results 
of the study, it can be inferred that the addition of oxalic acid and glycine to soil can be recommended as beneficial nutrient supplement [3].

\section{Conflict of interest statement}

The author declares that the research was conducted in the absence of any commercial or financial relationships that could be construed as a potential conflict of interest.

\section{References}

1. L. Ström and L. Strom, Oikos., 80 (1997) 459. https://doi.org/10.2307/3546618.

2. F. Pan, Y. Liang, W. Zhang, J. Zhao and K. Wang, Front. Sci., 7 (2016) 1. https://doi.org/10.3389/fpls.2016.00687.

3. J. Song, D. Markewitz, Y. Liu, X. Liu, X. Cui, Forests, 7 (2016) 1. https://doi.org/10.3390/f7100213.

4. S. Taghdis, M. H. Mehrizi and V. Jalali, Comm., 3624 (2016).

https://doi.org/10.1080/00103624.2016.1254 789.

5. Y. Lv, G. Xu, J. Sun, M. Brestič, M. Živčák and H. Shao, Plant Soil Environ., 61 (2015) 339.

https://doi.org/10.17221/666/2014-PSE.

6. V. Vranova, K. Rejsek and P. Formanek, Sci. J., 2013 (2013) 1.

https://doi.org/http://dx.doi.org/10.1155/201 3/524239.

7. M. S. Strickland, R. L. Mcculley, J. A. Nelson and M. A. Bradford, Front. Microbiol., 6 (2015) 1. https://doi.org/10.3389/fmicb.2015.00817.

8. M. L. Dotaniya, S. C. Datta, D. R. Biswas, H. M. Meena and K. Kumar, Natl. Acad. Sci. Lett., 37 (2014) 401. https://doi.org/10.1007/s40009-014-0254-3.
9. K. G. de L. Dias, A. E. F. Neto, P. T. G. Guimarães, T. H. P. Reis, C. H. C. de Oliveira, G. L. De, P. To and P. By, Cienc. Agrotec. Lavras., 39 (2015) 110.

10. F. Zhu, X. Lu, L. Liu and J. Mo, Sci. Rep., 5 (2015) 19. https://doi.org/10.1038/srep07923.

11. M. K. Souri, Open Agric., 1 (2016) 118. https://doi.org/10.1515/opag-2016-0016.

12. Y. Wang, X. Chen, J. K. Whalen, Y. Cao, Z. Quan, C. Lu and Y. Shi, J. Plant Nutr. Soil Sci., 178 (2015) 555. https://doi.org/10.1002/jpln.201500047.

13. S. Ganesh, F. Khan, M. K. Ahmed, P. Velavendan, N. K. Pandey and U. Kamachi Mudali, Water Sci. Technol., 66 (2012) 2653.

https://doi.org/10.2166/wst.2012.468.

14. S. Studenroth, S. G. Huber, K. Kotte and H. F. Schöler, Environ. Sci. Technol., 47 (2013) 1323.

https://doi.org/10.1021/es304208a.

15. S. B. Durman, A. B. Menendez and A. M. Godeas, 37 (2005) 2180.

https://doi.org/10.1016/j.soilbio.2005.03.017.

16. T. Watanabe and M. Osaki, Tree Physiol., 22 (2002) 785.

https://doi.org/10.1093/treephys/22.11.785.

17. B. Båth and E. Otabbong, Acta Agric. Scand. Sect. B Soil Plant Sci., 63 (2013) 483.

https://doi.org/10.1080/09064710.2013.804115.

18. S. X. Tu, Z. F. Guo and J. H. Sun, Pedosphere, 17 (2007) 457.

https://doi.org/10.1016/S10020160(07)60055-1.

19. A. A. Khalil, ISRN Soil Sci., 2013 (2013) 1. https://doi.org/10.1155/2013/438949.

20. G. F. Mielki, R. F. Novais and J. C. Ker, Rev. Bras. Cienc. Do Solo., 40 (2016) 1. https://doi.org/10.1590/18069657rbcs20150 174. 